\title{
The Effectiveness of a Blended Strategy based on Concept Mapping and Text Structure in Enhancing EFL Learners' Writing Performance
}

\author{
Hassan M. Kassem \\ Tanta University, Egypt \& Shaqra University, Saudi Arabia \\ E-mail: hkassem2007@hotmail.com
}

P.O Box: 31527

Received: Jan. 23, 2017 Accepted: May 30, 2017 Published: May 30, 2017

doi:10.5296/jse.v7i2.11259 URL: https://doi.org/10.5296/jse.v7i2.11259

\begin{abstract}
The current study investigated the effect of a blended strategy based on concept mapping and text structure on EFL learners' writing performance. An intact group $(\mathrm{N}=42)$ of seventh level English majors at Thadiq Sciences and Humanities College, Shaqra University, KSA participated in the study in the first semester of the academic year 2016-2017. They were assigned to an experimental group and a control group, each consisting of 21 students. A writing pretest was administered to the two groups and scored by two raters using the Weir's TEEP attribute writing scale (1990). An independent samples t-test performed on the pretest mean scores of the two groups showed that they were homogenous prior to the experiment. Concept mapping and text formatting (the proposed blended strategy) were integrated in the Advanced Writing course (Eng 413) for experimental group students. The control group received conventional instruction that did not include the proposed strategy. Independent and paired samples t-tests revealed that the experimental group outperformed the control group in all the sub-scales of Weir's TEEP attribute writing scale, hence supporting the positive effect of concept mapping and text formatting on EFL learners' writing performance. Pedagogical implications are offered.
\end{abstract}

Keywords: EFL writing performance, concept mapping, text structure, English majors. 


\section{Introduction}

Writing is the most challenging skill for all language learners (Nunan, 2000; Kellogg, 2008). It, as Nunan (2000) and Brown (2001) assert, does not develop naturally. That is, it does not arise out of a vacuum (Hazel, 2005). The demanding nature of writing is attributable to the fact that it requires complicated cognitive and linguistic operations and strategies (Peregoy \& Boyle, 2005; Hedge 2008). The ability to produce a coherent piece of writing, therefore, does not develop by itself. It needs to be deliberately taught and learned. The reason for this is that writing, as Langan (2008) put it, is not an automatic process. Rather, it is a complex process that needs a skill from the moment a writer starts to think about what to write until the written text is produced (Richards, 1990). Knowing what to write and how to write it seem to be a challenging task for all language learners. Thus, when asked to produce a piece of writing, many learners tend to procrastinate because they do not know how to begin and cannot think of anything to say about the topic at hand (Smalley, et al., 2001). This applies to all language learners, even native speakers. Nunan (2001) asserts this by arguing that producing a coherent, fluent, and extended piece of writing is probably an aim that sometimes most native speakers never master.

If writing is demanding for L1 and L2 learners, it is daunting for FL learners. Richards \& Renadya (2002: 303) contend that writing is a huge task for FL learners because the skills involved in writing are highly complex and learners have to "pay attention to higher level skills of planning and organizing as well as lower level skills of spelling, punctuation, word choice, and so on." Concurring with this theoretical claim, a large number of studies identified the specific difficulties that Arab EFL learners have when writing in the FL (e.g., Ahamed, 2016; Abu Rass, 2015; Al Seyabil \&Tuzlukova, 2014; Javid \& Umer, 2014; Baka, 2013; Zakaria \& Mugaddam, 2013; Salem, 2007). For instance, Zakaria and Mugaddam (2013) investigated the writing performance of 240 Sudanese fourth level students majoring in English at five universities. Analysis showed that students did not use writing strategies such as planning and organization. Students also proved to lack awareness of cohesive devices and to produce disconnected sentences and incoherent paragraphs. In a similar study, Javid and Umer (2014) reported that 194 Saudi EFL learners studying at Taif University have serious problems in their academic writing due to their weaknesses in using appropriate lexical items and organization of ideas. Similarly, Abu Rass (2015) reported that Palestinian Arab students from Israel who are majoring in teaching English as a Foreign Language have problems with providing supporting details such as examples and reasons and with developing cohesive paragraphs by using the right coordinators and transition words.

In the face of the complicated nature of the writing task and in order to promote learners' writing performance, strategy instruction has been widely used and proved effective in different language settings (e.g., Meghyasi \& Hashamdar, 2015; Al-Shaer, 2014; Negari, 2011; Pishghadam \& Ghanizadeh, 2006; Al-Jarf, 2009; Ojima, 2006). According to the strategy instruction approach, learners are trained on evidence-based strategies in the main stages of writing: planning, drafting, revising and editing. A writing strategy that proved to have good reflection on learners' writing performance is concept mapping. Concept mapping is a strategy that enables writers to visually represent their knowledge of a topic and graphically illustrate the relationships among ideas (Zimmaro \& Cawley (1998). This 
pre-writing strategy stimulates writer's thoughts, so they will not confront a "blank page" (Seow, 2002: 315; Kroll, 2001: 223) as a result of knowing little about the topic. It also sensitizes writers to the relationships among ideas and the way to develop them in a well-organized piece of writing. Knowing what to write and how to write it reduce the cognitive load on short-term memory (De La Paz \& Graham, 2002), which, according to Ellis and Yuan (2004), allows greater attention to the next stage where writers select lexical units and syntactic frames needed to encode ideas. Unfortunately, SL and FL language learners are not used to this kind of planning before they write, and this results in their being less fluent and making more errors and less effort in creating well-organized material (Brown, 2007). This refers to the significance of training learners on pre-writing planning that can be achieved via concept mapping and similar strategies.

Knowledge of text structures has also been theoretically claimed to have a good refection on writers' performance. For example, Grabe (2009) argues that students need to know that texts are not made of discrete sentences but they have rhetorical structures that organize information in a way that serve writers' purposes. For this reason, Grabe (2002: 236) calls for explicit teaching of text structures, "a more coherent and focused effort to teach expository writing and to practice such writing consistently would improve students' writing abilities." In this same respect, Meyer and Poon (2001) regard content knowledge as important but not sufficient for writing good expository texts. Students also need to know how to organize the content to meet the writing task demands. Research confirmed this theoretical claim that instruction in the organizational patterns of texts improves SL and FL learners' writing (e.g., Amer, 2013; Meghyasi \& Hashamdar, 2015).

\section{Statement of the problem}

The researcher of the present study has been teaching EFL writing courses to English majors at the College of Sciences and Humanities at Shaqra University, KSA for several years. Throughout these years, the researcher noticed that students face many difficulties with EFL writing, especially when asked to write essays. Apart from producing accurate English, they often complain that when they are asked to write extended pieces of writing, they cannot generate sufficient ideas to write about. That is, they confront what Seow (2002: 315) and Kroll (2001: 223) call the "blank page." And in case they have ideas to write about, they cannot organize them in well-developed essays. Owing to these two serious problems, they often end up with disconnected sentences, incoherent paragraphs and poorly-developed pieces of writing. Preoccupied with idea generation and development during the writing task, their writing products show many syntactic errors. It is worth mentioning that this seems to be a phenomenon in the Saudi context. Several studies reported these problems in many Saudi samples from various universities. For instance, Baka (2013) reported weak writing performance among a comparable sample of 874 English majors at King Faisal University. Ahamed (2016) investigated the writing weaknesses of Saudi EFL university students of College of Science \& Arts, Tanumah at King Khalid University. He found that $75 \%$ of the students did not write introduction, $60 \%$ did not paragraph their essays, $70 \%$ did not write a coherent essay, $70 \%$ did not use transition words, and $90 \%$ did not write conclusion.

In order to know about the major reasons for students' poor writing performance, the researcher conducted several discussions with them. A significant discovery was that students 
did not plan before they write. They confirmed that they were never taught to plan before they write in any time in their previous years of education. Therefore, their minds wander while writing and they run out of ideas, which affect the writing task negatively. This concurs with a research finding (Bourdin \& Fayol, 2000; Brown, 2007; Evans \& Green, 2007) that poor writers do less planning than more successful ones, and that insufficient planning lead to poor writing performance. Another discovery that the present researcher came up with through discussions with students is that they lack knowledge of text rhetorical structures. Lack of this knowledge can result in students' writing being disorganized and poorly-developed. Conversely, when students know about the distinctive features of common text structures, they take advantage of this knowledge to make their writing coherent and well-developed (Amer, 2013; Meghyasi \& Hashamdar, 2015).

With these reasons for students' weak EFL writing in mind, the researcher initiated an action research and surveyed relevant literature in search for effective solutions. Concept mapping seemed to be the most widely-used and effective strategy for pre-writing planning. Exploitation of knowledge of text structures also proved to be a common and effective practice in effective writing classes. Accordingly, the researcher proposed a writing strategy that combines both concept mapping and text structure. This blended strategy is expected to lead to better results as it combines two effective strategies in one strategy with fixed procedures. It is postulated that if students are trained on developing concept maps and in the same time on making use of their knowledge of text structures to organize the ideas in the maps they produce in well-developed pieces of writing, their writing will show better improvement than when they are trained on either of them or both of them but each one at a time. More specifically, the study addressed the following question, "Is a blended strategy based on concept mapping and text structure effective in enhancing EFL learners' writing performance in terms of communicative effectiveness (relevance \& adequacy of content, compositional organization, cohesion, \& adequacy of vocabulary for purpose) and accuracy (grammar, punctuation and spelling)?"

\section{Review of literature}

\subsection{The challenging nature of EFL writing for Arab students}

Writing academic essays is not an easy task since it "requires much more than good surface writing skills such as producing grammatically correct sentences" (Villalon \& Calve, 2011:17). For this reason L2 and FL students usually face problems with academic writing because it is not easy for them to express themselves clearly and write according to the flow of ideas (Basturkmen \& Lewis, 2002). Arab students are not an exception. They face many difficulties writing well-developed paragraphs and essays in English (Abu Rass, 2015). Review of literature reveals that Arab students have a host of difficulties with EFL writing. In this section, a few studies conducted in different Arabic countries will be surveyed. Beginning with the Saudi context, which is the context of the present study, Javid and Umer (2014) reported that 194 Saudi EFL learners studying at Taif University had serious problems in their academic writing due to their weaknesses in using appropriate lexical items and organization of ideas. Similarly, Ahamed (2016) investigated the writing weaknesses of Saudi EFL university students of College of Science \& Arts, Tanumah at King Khalid University. He found that $75 \%$ of the students did not write introduction, $60 \%$ did not 
paragraph their essays, 70\% did not write a coherent essay, $70 \%$ did not use transition words, and $90 \%$ did not write conclusion. Zakaria and Mugaddam (2013) investigated the writing performance of 240 Sudanese fourth level students majoring in English at five universities. Analysis showed that students did not use writing strategies such as planning and organization. Students also proved to lack awareness of cohesive devices and to produce disconnected sentences and incoherent paragraphs. Abu Rass (2015) reported that Palestinian Arab students from Israel who are majoring in teaching English as a Foreign Language have problems with providing supporting details such as examples and reasons and with developing cohesive paragraphs by using the right coordinators and transition words.

In a self-report study, Al Seyabil and Tuzlukova (2014) investigated the problems that Omani school and university students face in writing. Five main types of writing problems were investigated: deciding how to start an essay/paragraph, not knowing how to write a correct English sentence, putting the ideas together in a coherent way, choosing the right vocabulary to express their ideas, and not having enough ideas about the topics that their teachers ask them to write about. Of these five areas, not having enough ideas was perceived to be the biggest problem for university students (mean =3.66). Salem (2007) explored the views of 50 male undergraduate students majoring in English in relation to writing in English at the University Of Al-Azhar, Egypt. Most of the students felt overwhelmed when they were required to write in English. They did not know how to start, how to develop their ideas or how to conclude the essay. They also lacked the technical skills of writing acceptable compositions in English. They often repeated their ideas, reported few if any valid points, made serious mistakes in grammar and punctuation, and included irrelevant information. Similarly, Ahmed (2010) investigated cohesion and coherence problems in EFL essay writing in the Egyptian context. He reported that the students faced difficulties writing thesis statements, topic sentences, transitioning of ideas, and the sequencing of ideas. Doushaq (1986) conducted a study investigating the writing problems of Jordanian Arab university students, and noted that the main problems lay at the sentence and paragraph level, and that there were also problems of content.

Several studies were also conducted to identify reasons for Arab students' poor EFL writing proficiency. Talking of the Saudi context, Al-Khasawneh and Huwari, (2013) attributed Saudi EFL students' limited writing proficiency to limited knowledge, understanding and practice, and to grammatical weakness. Other researchers reported limited exposure to the target language and poor reading base as the main reasons for Saudi students' being limited in their thoughts when they write in English (Shukri, 2014). This lack of input, as maintained by Zhang (2009), is a common reason for L2 and FL students' limited language proficiency in general and writing proficiency in particular. Almarwany (2008) found that many writing difficulties (in grammar, organization, capitalization and punctuation) faced by Saudi students are due to the effect of their first language. As a result of their limited language proficiency, students apply L1 rules without realizing that L1 and L2 have different systems. Learning and teaching have also been identified as causes of the problem. Saudi EFL learners are more interested in getting better scores than in learning the target language (i.e., they lack intrinsic motivation). They seek to achieve this by rote memorization of passages, grammatical rules and lexical items. This concurs with Richardson's observation (2004) 
about Arab students' preference for prescriptive learning environments where they are told exactly what to do and about their resistance to taking more responsibility for their learning. EFL teachers, who are hired from other Arab countries, seem to lack willingness to incorporate innovative techniques in their teaching practices (Grami, 2010). Another important factor in this regard is lack of appropriate and learner-centered curricula. It has been frequently reported that curricula in several Saudi university are traditional and textbook-based that focus more on rote learning than on meaningful learning (Khan, 2011).

In brief, the review of literature on the difficulties Saudi students face with EFL writing and the reasons for them indicates that the product approach (rather than the process approach) is the dominant approach used for EFL writing in the Saudi context. This stresses the need to integrate the process approach that fosters active learning on the part of students in writing classes. At the heart of this comes the use of research-based writing strategies such as concept mapping. By mastering such strategies, students become more responsible for their own learning, which is of a great significance in English input-poor environments like the Saudi one.

\subsection{Concept mapping}

Review of literature reveals that graphical representation of ideas and the relationship among them is the most frequent pre-writing activity in language classrooms. This practice, according to Fisher (1995) is what is meant by numerous terms: concept mapping, semantic webbing, semantic mapping, knowledge mapping, word webbing, networking, clustering, mind maps, think-links, idea branches, graphic organizers, semantic networking, or plot maps. The concept map, one of the most frequent terms, refers to graphical representation and organization of knowledge. The idea of the concept map was originally derived from cognitive theory which sprang out of Ausubel's assimilation theory (Novak and Cañas, 2006). It consists of concepts or nodes enclosed in circles or boxes and linked by labeled lines to show relationships and inter-relationships among concepts (Novak, \& Cañas, 2008; Villalon $\&$ Calvo, 2011). Concept maps allow students to understand the relationships among ideas by creating a visual map of the connections (Cañas, Hoffman, Coffey \& Novak, 2003). They help students by getting them to generate ideas, see the relationships among them and group related concepts in propositions or semantic units (Villalon \& Calvo, 2011; Padang and Gurning, 2014). Lee (2013) mentions another benefit of concept maps. She asserts that concept maps have a positive psychological effect on students, i.e., they make them more self-confident or less apprehensive about the actual writing task. Thus in studies where researchers groped students' reaction towards concept mapping, students reported positive perceptions and asserted that it is fun, motivating and supportive of their writing performance (Goodnough \& Woods, 2002; Al-Jarf, 2009; Machida \& Dalsky, 2014; Yunus \& Chien, 2016).

Novak (2004: 154) identified the following steps for constructing concept maps. First, the key concepts are listed. Second, concepts are rank ordered by placing the broadest at the top of the map and the most specific at the bottom. Third, concepts are connected by lines which are labeled by linking words. The linking words should define the relationship between the two concepts so that it makes a proposition. Concept maps can be constructed individually or collaboratively. Research findings concerning the relative effect of individually and 
collaboratively constructed concept maps are mixed. Several studies have reported that students who collaboratively generate concept maps outperform those who construct concept maps individually (Okebukola, 1989; Okebukola, 1992; Brown, 2003). Paykoç, Mengi, Kamay, Onkol, Ozgur, Pilli, and Yildirim (2004) reflect on this asserting that group concept mapping enhances critical thinking and co-operation and provides a solid basis for collaborative problem-solving. Conversely, peer collaboration for constructing concept maps did not improve composition scores in a study conducted by Lee (2013). The researcher explained this finding using Chiu's (2004) conclusion that "group members' conflicts in completing collaborative tasks may obstruct students' learning." And in some other studies, individually constructed concept maps proved more effective than collaboratively constructed ones (Arabloo, 2015). However, it seems that when either, individual or collaborative concept mapping, is compared to conditions without concept maps, they prove to be more effective. For this reason, Schwendimann (2015) recommends that instructors make informed decisions about which form of concept maps, from individual usage to small groups and whole class discussions, suits which task and learner. Thus, if both ways of constructing concept maps have advantages, it is a good option to employ both of them. In some studies, students construct maps individually before they discuss them in groups. Another alternative is to get students construct maps collaboratively in class and individually at home in the form of assignments.

Three common approaches are used for teaching strategies. The most widely used of these approaches is explicit or direct teaching where learners are given information about the value and purpose of strategies, taught how to use them and how to monitor their use. Another approach is embedded strategy training where the strategies are embedded in the regular content of an academic subject area. The third approach combines these two approaches where explicit strategy training is followed by embedded training (Richards, Platt, \& Platt, 1992: 355). Several models were developed for direct teaching of strategies. An example of these models is Macaro's (2001: 262) model that has nine steps. These are raising students' awareness of the strategies, exploration of the strategies available, modeling strategies, combining strategies for a specific task, application of strategies with scaffolded support, initial evaluation of strategy training, gradual removal of scaffolding, overview evaluation, and monitoring of strategy use and rewarding effort. One of the most widely used models for strategy teaching is the one proposed by Harris and Graham (1996). This models proceeds in this sequence: a description of the strategy, discussion of its goals and purposes, modeling of the strategy by the teacher, mastery of strategy steps by students, and guided practice and feedback.

Research has supported the effectiveness of the direct teaching of concept mapping on L1, L2 and FL learners' writing performance (e.g., Ojima, 2006; Pishghadam \& Ghanizadeh, 2006; Al-Jarf, 2009; Negari, 2011; Riswanto \& Putra, 2012; Nobahar \& Tabrizi, 2013; Al-Shaer, 2014; Saed \& AL-Omari, 2014; Padang \& Gurning, 2014; Payman \& Gorjian, 2014; Meghyasi \& Hashamdar, 2015; Thayniath, 2015; Shakoori, Kadivar \& Sarami, 2017). Talking of the FL setting, Al-Jarf (2009) investigated the impact of using a mind mapping software on Saudi EFL university freshmen's writing skills. Findings revealed that the written work produced by students who were trained on mind mapping included more 
relevant details and better organized and connected ideas than the work produced by the control group students. Mind mapping raised the performance of students at all levels of ability as they became more efficient in generating and organizing ideas for their writing. Students also displayed a positive attitude towards using mind mapping as a pre-writing activity. Pishghadam and Ghanizadeh (2006) investigated the impact of concept mapping as a pre-writing activity on EFL learners' writing ability. Students in the experimental group outperformed students in the control group in terms of quantity and quality of generating, organizing, and associating ideas. Similarly, Al-Shaer (2014) examined the effect of concept mapping on EFL learners' ability to write better argumentative essays. Thirty-eight participants were randomly assigned to two groups participating in a writing course at Al-Quds Open University. Both groups were taught by the same teacher. The control group received conventional instruction, whereas the experimental group was taught to construct concept maps. Statistical comparison revealed a statistically significant improvement in the experimental learners' ability to generate better argumentative essays in terms of point of view, unity and coherence, development, organization, and thinking. In a similar study, Meghyasi and Hashamdar (2015) reported a significant positive effect of explicit instruction of concept mapping on 60 intermediate EFL Iranian learners' descriptive and persuasive writings.

In a study by Nobahar and Tabrizi (2013), 60 intermediate EFL learners were randomly assigned to a control group and an experimental. Only experimental group students were involved in concept mapping for 15 minutes in the course of 22 sessions. Instruction in the control group did not include the concept mapping component. Results showed that concept mapping had a significant effect on self- efficacy and expository writing accuracy. In a study that explored the effect of concept mapping in compassion with other pre-writing strategies, Payman and Gorjian (2014) tested the hypothesis that class discussion, oral summary, and mind mapping may develop EFL learners' writing proficiency. Ninety translation students were selected (out of 120 Translation students at Abadan University, Iran) and randomly divided into three groups: class discussion, oral summary, and mind mapping. One-way ANOVA and Paired Samples t-tests revealed that mind mapping and class discussion groups outperformed the oral summary group. However, the mind mapping group outperformed both groups.

\subsection{Text structure}

Linguistically, a text is not just a series of discrete sentences and paragraphs. Rather, it follows a certain hierarchy, which supports a superordinate thesis by subordinate major details and further subordinates interrelates and sequences the very specific details on the topic. Expository texts are texts that are used by the authors to give information, to explain, to describe, or to persuade (Gaddy, Bakken \& Fulk, 2008). Taylor and Beach (1984) and Dymock (2005) contend that lack of knowledge about text organization can result in students having difficulty with expository writing. As a result, Grabe (2002: 263) asserts that "a more coherent and focused effort to teach expository writing and to practice such writing consistently would improve students' writing abilities." Reppen (1995: 32) holds that students who are aware of the features of different text types "learn the language needed to talk about texts, begin to understand how and why texts are organized in certain ways." 
Reppen (1995: 32) further contends that writing is "important for English L1 students and crucial for English L2 learners... simply allowing students to write a lot will not necessarily provide sufficient practice in the types of writing valued for academic writing." Raphael and Kirschner (1985) believe that knowledge of text structure helps writers in many ways: (1) explore the subject, (2) clarify the purpose, (3) make decisions about how to arrange ideas and information, and (4) revise the ways ideas are presented. The significance of text structure knowledge urged researchers to develop techniques to utilize such knowledge for comprehension and production of expository texts. Geva's Flowchart (1983), Taylor-Beach's (1984) Summarization Skelton and Spring-Prager's (1992) Train of Thought are just examples.

Knowledge of text structures proved to have positive effects on writing proficiency (e.g., Raphael \& Kirschner, 1985; Amer, 2013). Several studies were conducted on the correlation between explicit instruction of expository writing structures and writing performance. For instance, a study by Raphael and Kirschner (1985) revealed that students receiving instruction in expository text structure made significant improvement in their free writing, and made specific improvement in writing comparison/contrast text structures which had been found to be particularly difficult. Similarly, in an action research, Amer (2013) investigated the relationship between explicit instruction in the organizational pattern of comparison- contrast and EFL writing performance. Twenty two Palestinian EFL university students enrolled in an academic writing course participated in the study. The study spanned over three weeks during which the subjects received nine hours of explicit instruction in the organizational structure of compare/contrast text. Data pointed to a direct correlation between direct teaching of text structure and improved writing performance. The interviews with participants provided evidence that students felt more comfortable and confident about writing when they are explicitly taught the organizational structures of expository texts. Henry and Roseberry (1998) taught a group of students about genres for three weeks. The genre group did better than the non-genre group, and the data showed that knowledge of the typical structure of the content made it easier for learners to arrange their ideas in terms of both achieving their communicative goals and producing more well-organized writing.

In the present study, students would be trained in developing text formats immediately after they produce concept maps. This hopefully would keep students focused on the target text structure. It could also help students to convert propositions in maps into sentences. Without such a format, students may face difficulty converting map propositions into sentences. Furthermore, it could alert students to the use of conjunctions and transition signals, which helps to make compositions more coherent.

\section{Methodology}

\subsection{Participants}

An intact group of 42 seventh level English majors at Thadiq Sciences and Humanities College, Shaqra University, KSA participated in the present study. They were enrolled in the Advanced Writing Course (Eng 413). In this course, students learn about and practice writing different types of essays, e.g., argumentative, cause and effect, comparison and contrast. They learn about text structure, read and analyze sample texts, and do controlled practices like deciding on the best thesis statement among several options, relevant and irrelevant 
supporting detail, as well as the use of conjunctions and transition signals within each type of text. However, they are not trained on concept mapping as a pre-writing activity. They just learn about text structure, do controlled practices such as the ones mentioned above, read exemplary texts, and write essays using the chapter's target text structures as home assignments. All the 42 participants were male students (for there is segregation in Saudi universities). Their average age was 21 years. They had the same language experience in terms of years of study and rate of exposure to the language. The 42 students were randomly assigned to an experimental group and a control group, each having 21 students.

\subsection{Instruments}

A writing test was developed to assess students' composition before and after the treatment. The students were asked to write about 150 words on the topic "Is internet education a better alternative to traditional education?" Using the same topic in pre- and post-testing was thought to be more reliable than using two different topics, so the differences between the two test topics would not affect results. And a six-week interval was allegedly thought to be enough to wash the effect of the pretest on the posttest (traditionally 2 weeks are enough to achieve this aim). Besides, the test was applied to the two groups, so there was no bias for or against any group.

The researcher surveyed writing assessment profiles and scales to develop or adapt rating rubrics for the present study. Examining three of the most widely used assessment schemes (namely, Jacobs, Zinkgraf, Wormuth, Hartfiel, \& Hughey, 1981; Weigle, 2002; and Wier, 1990), the researcher decided that Weir's scheme fitted the purpose of the current study the best. Besides, the researcher found it simple and easy to apply. Weir's TEEP attribute writing scale (1990) was used to measure the quality of students' composition (See appendices). This scale consists of 7 sub-scales, each divided into 4 levels with score points ranging from 0 to 3 . The first 4 scales (relevance and adequacy of content, compositional organization, cohesion, and adequacy of vocabulary for purpose) relate to communicative effectiveness, while the others (grammar, punctuation and spelling) relate to accuracy. This scale, as confirmed by Weigle (202: 115), "was extensively piloted and revised to make sure that it could be applied reliably by trained raters."

\subsection{Pre-testing}

Students took the pretest in 90 minutes. Most similar studies give student only 60 minutes to write about the test topic. The researcher of the present study added 30 minutes for students to plan before they write. Two experienced instructors who have taught writing for several years scored the collected essays. Before scoring the data, the raters discussed the rating rubrics to make sure they have a shared understanding of it. Raters' scores were then tested for inter-rater reliability. Inter-rater correlations were computed (all statistical work was done using the SPSS program). The correlation coefficient was (.923). This high agreement meant that the two raters were quite consistent with how they assessed the students' essays. Sums of the two raters' scores were used. This was thought to be more accurate than averaging scores, which could yield fractions. Factions would need to be rounded, which means adding or deducting up to half a score from students. 
In order to make sure the two groups were homogeneous prior to the experiment, an independent-samples t-test was performed to compare the mean scores of the two groups on the writing pre-test. The resulting $\mathrm{t}$-values indicated that the two groups were homogeneous before the experiment concerning the score of the individual assessment dimensions and the total score. That is, the two groups were homogenous before the experiment. The following table shows the data of this statistics.

Table 1. Means, standard deviations and t-values for the pretest mean differences between the two groups

\begin{tabular}{|l|l|l|l|l|l|l|}
\hline Test & Group & $\mathrm{N}$ & $\mathrm{M}$ & $\mathrm{SD}$ & $\mathrm{T}$ & Sig. \\
\hline \multirow{2}{*}{ Relevance \& adequacy of content } & Control & 21 & 2.38 & 1.16 & -.45 & .687 \\
& Experimental & 21 & 2.52 & 1.12 & -.405 & \\
Compositional organization & Control & 21 & 1.95 & 1.28 & & \\
Cohesion & Experimental & 21 & 2.00 & 1.37 & -.116 & .908 \\
Adequacy of vocabulary for purpose & Control & 21 & 2.23 & 1.09 & & \\
& Experimental & 21 & 2.09 & 1.17 & .407 & .686 \\
Grammar & Control & 21 & 2.62 & .92 & & \\
& Experimental & 21 & 2.81 & .98 & -.649 & .520 \\
Punctuation & Control & 21 & 2.43 & 1.0 & -.755 & .455 \\
Spelling & Experimental & 21 & 2.67 & 1.0 & & \\
& Control & 21 & 2.95 & .86 & -1.49 & .145 \\
Total & Experimental & 21 & 2.33 & .79 & & \\
& Control & 21 & 2.62 & .92 & .344 & .733 \\
& Experimental & 21 & 2.52 & .87 & & \\
& Control & 21 & 17.19 & 5.9 & -.447 & .658 \\
\hline
\end{tabular}

\subsection{Training procedures}

The Essay Writing Course is allocated three hours a week. Students study five chapters in the course, each dealing with a text structure (argument, cause and effect, comparison and contrast, description, and problem and solution). Hence, each text structure is allocated 3 weeks (i.e., 9 hours). The experiment covered only two text structures (argument and cause and effect) over six weeks, in addition to the two testing sessions. The researcher taught the two groups. Students in the two groups studied the same material for the same amount of time. However, only students in the experimental group were trained in concept mapping and converting propositions in maps into formats representing the target text structures before they actually produce essays. The time taken for this training was saved by skipping some repetitive practices and getting students to write essays at home (control group students wrote most essays in the classroom).

Training was implemented in four main steps that seem to be common to all direct teaching models. First, students were given an idea about the target strategy: what it is, when it can be used and why it is useful (strategy description). Second, the researcher modeled the strategy for students. The researcher identified a topic and while thinking aloud developed a concept 
map (or a text format) for it. During this step, students proposed ideas that the researcher incorporated in the map. Third, students, in groups, developed concept maps (or text formats) with the researcher scaffolding them when necessary. Finally, students individually and independently developed concept maps and text formats.

More specifically, during the first session, the researcher taught students about concept mapping and modeled it by developing a concept map for the topic "The segregation of poor students in separate classrooms." Then, he taught them about text formatting and modeled it by producing a text format for the same topic. Then he gave them a handout containing the concept map, the text format and the essay based on them (See appendices for this package). The researcher, then, identified the topic "should animals not be used in experiments" and instructed them to work in groups of four to develop a concept map and a text format for it. As they worked on the map and the format, the researcher moved about to monitor their work and to help whoever needed help. The researcher instructed them to photocopy the produced map and format, so that each member got a copy to use when writing the essay at home. Finally, the researcher identified the topic "Should parents be held responsible for their children's crimes?" and instructed them to individually develop a concept map and a text format for it. Again the researcher provided individual students with any required guidance. As a home assignment, students were instructed to write two essays based on the maps and formats they had and submit the essays one day before the following week's session. At the beginning of the following week's session, the researcher handed students their marked essays (with written feedback) and made a general comment on the essays written by all the students. Then, another session was initiated following the same procedure of the first session, but with different topics, maps and formats.

The training procedures described above for the first session were repeated in the other two sessions that focused on argumentative essays and in the three sessions for cause and effect essays. Since students wrote two essays for each session, they wrote a total of twelve essays during the experiment. It is noteworthy that control group students wrote the same essays, but after doing activities that did not include concept mapping and text formatting.

\subsection{Post-testing}

Students took the posttest and two experienced instructors who have taught writing for several years scored the collected essays. Inter-rater correlations were computed. The correlation coefficient was (.909). This high agreement meant that the two raters were quite consistent with how they assessed the students' essays. Sums of the two raters' scores were used.

\section{Results}

The scores of the two groups on the writing posttest were compared using the independent-samples t-test. Significant differences were found between the two groups in six of the seven sub-scales and the whole scale in favor of the experimental group. More specifically, at the end of the experiment, the experimental group outperformed the control group in relevance and adequacy of content $(\mathrm{t}(40)=4.48, \mathrm{p}=.000)$, compositional organization $(\mathrm{t}(40)=5.02, \mathrm{p}=.000)$, coherence $(\mathrm{t}(40)=3.52, \mathrm{p}=.001)$, vocabulary $(\mathrm{t}(40)=$ 


\section{Macrothink}

$3.68, \mathrm{p}=.001)$, grammar $(\mathrm{t}(40)=2.44, \mathrm{p}=.019)$, punctuation $(\mathrm{t}(40)=2.56, \mathrm{p}=.014)$, and the whole scale $(\mathrm{t}(40)=4.72, \mathrm{p}=.000)$. The two groups did not differ significantly in spelling $(\mathrm{t}(40)=1.32, \mathrm{p}=.194)$. These results are summarized in Table 2 below.

Table 2. Means, standard deviations and t-values for the posttest mean differences between two groups

\begin{tabular}{|l|l|l|l|l|l|l|}
\hline Test & Group & $\mathrm{N}$ & $\mathrm{M}$ & $\mathrm{SD}$ & $\mathrm{T}$ & Sig. \\
\hline \multirow{3}{*}{ Relevance \& adequacy of content } & control & 21 & 2.81 & .813 & -4.48 & $\mathbf{. 0 0 0}$ \\
& Experimental & 21 & 3.90 & .768 & & \\
Compositional organization & control & 21 & 2.28 & .784 & & \\
& Experimental & 21 & 3.52 & .813 & -5.02 & $\mathbf{. 0 0 0}$ \\
Adequacy of vocabulary for purpose & control & 21 & 2.43 & .870 & -3.52 & $\mathbf{. 0 0 1}$ \\
Grammar & Experimental & 21 & 3.33 & .796 & & \\
Punctuation & Experimental & 21 & 3.52 & .512 & -3.68 & $\mathbf{. 0 0 1}$ \\
Spelling & control & 21 & 2.67 & .856 & -2.44 & $\mathbf{. 0 1 9}$ \\
Total & Experimental & 21 & 3.28 & .784 & & \\
& control & 21 & 3.24 & .700 & \multirow{2}{*}{-2.56} & $\mathbf{. 0 1 4}$ \\
& Experimental & 21 & 3.76 & .625 & & \\
& control & 21 & 3.05 & .669 & & \\
& Experimental & 21 & 3.33 & .730 & -1.32 & .194 \\
& control & 21 & 19.33 & 4.066 & & \\
& Experimental & 21 & 24.67 & 3.199 & -4.72 & $\mathbf{. 0 0 0}$ \\
\hline
\end{tabular}

To get an idea about the gains students in the two groups attained from pre- to post-testing, a paired-samples t-test was performed on the students' scores on the pretest and the posttest. Table 3 below includes the data concerning the comparison between the writing performance of the control group students before and after the experiment. 
Table 3. Paired samples t- test for the control group pre- and post- tests

\begin{tabular}{|l|l|l|l|l|l|l|}
\hline Test & $\mathrm{M}$ & $\mathrm{SD}$ & $\begin{array}{l}\text { Std. Error } \\
\text { Mean }\end{array}$ & $\mathrm{T}$ & df & $\begin{array}{l}\text { Sig. } \\
(2 \text {-tailed }\end{array}$ \\
\hline Relevance \& adequacy of content & -.428 & .811 & .177 & -2.42 & 20 & $\mathbf{. 0 2 5}$ \\
Compositional organization & -.333 & .796 & .174 & -1.92 & 20 & .069 \\
Cohesion & -.190 & .511 & .112 & -1.71 & 20 & .104 \\
Adequacy of vocabulary for purpose & -.238 & .700 & .153 & -1.56 & 20 & .135 \\
Grammar & -.238 & .569 & .128 & -1.22 & 20 & .065 \\
Punctuation & -.286 & .560 & .122 & -2.33 & 20 & $\mathbf{. 0 3 0}$ \\
Spelling & -.428 & .598 & .130 & -3.29 & 20 & $\mathbf{. 0 0 4}$ \\
Total & -1.14 & 2.69 & .587 & -1.95 & 20 & .066 \\
\hline
\end{tabular}

Data in table 3 above reveal that the difference between the pre- and post-test total mean scores of the control group was not significant $(\mathrm{t}(20)=1.95, \mathrm{p}=.066)$. Nor were the differences significant concerning compositional organization $(\mathrm{t}(20)=1.92, \mathrm{p}=.069)$, cohesion $(\mathrm{t}(20)=1.71, \mathrm{p}=.104)$, adequacy of vocabulary for purpose $(\mathrm{t}(20)=1.56, \mathrm{p}$ $=.135)$, and grammar $(\mathrm{t}(20)=1.22, \mathrm{p}=.065)$. However, the control group achieved significant gains from pre- to post-testing concerning relevance and adequacy of content $(\mathrm{t}$ $(20)=2.42, \mathrm{p}=.025)$, punctuation $(\mathrm{t}(20)=2.33, \mathrm{p}=.030)$ and spelling $(\mathrm{t}(20)=3.29, \mathrm{p}$ $=.004)$.

Table 4 below shows the data concerning the comparison between the writing performance of the experimental group students before and after the experiment.

Table 4. Paired samples t- test for the experimental group pre- and post- tests

\begin{tabular}{|c|c|c|c|c|c|c|}
\hline Test & M & SD & $\begin{array}{ll}\text { Std. } & \text { Error } \\
\text { Mean } & \\
\end{array}$ & $\mathrm{T}$ & df & $\begin{array}{l}\text { Sig. } \\
\text { (2-tailed }\end{array}$ \\
\hline Relevance $\&$ adequacy of content & -1.38 & .973 & .212 & -6.50 & 20 & .000 \\
\hline Compositional organization & -1.52 & 1.401 & .306 & -4.98 & 20 & .000 \\
\hline Cohesion & -1.24 & .944 & .206 & -6.01 & 20 & .000 \\
\hline Adequacy of vocabulary for purpose & -.714 & .956 & .209 & -3.42 & 20 & .003 \\
\hline Grammar & -.619 & .805 & .176 & -3.52 & 20 & .002 \\
\hline Punctuation & -.428 & .926 & .202 & -2.12 & 20 & .047 \\
\hline Spelling & -.809 & .873 & .190 & -4.25 & 20 & .000 \\
\hline Total & -4.71 & 3.56 & .778 & -6.06 & 20 & .000 \\
\hline
\end{tabular}

It is clear from data in table 4 that the experimental group achieved significant gains from pre- to pot-testing in all sub-scales and the total score. All t-values were significant concerning Relevance \& adequacy of content ( $\mathrm{t}(20)=6.50, \mathrm{p}=.000)$, Compositional organization $(\mathrm{t}(20)=4.98, \mathrm{p}=.000)$, Cohesion $(\mathrm{t}(20)=6.01, \mathrm{p}=.000)$, Adequacy of 
vocabulary for purpose $(\mathrm{t}(20)=3.42, \mathrm{p}=.003)$, Grammar $(\mathrm{t}(20)=3.52, \mathrm{p}=.002)$, Punctuation $(\mathrm{t}(20)=2.12, \mathrm{p}=.047)$, Spelling $(\mathrm{t}(20)=4.25, \mathrm{p}=.000)$, and total score $(\mathrm{t}(20)$ $=6.06, \mathrm{p}=.000)$.

\section{Discussion}

The blended strategy that the researcher proposed and experimented with in the present study combines two research-based writing strategies, namely concept mapping and text formatting based on knowledge of text structure. Therefore, it is not surprising that it significantly enhanced learners' writing performance, bearing in mind that each strategy alone has been revealed to affect EFL writing positively. These findings are, therefore, in line with studies that reported positive effects of concept mapping (e.g., Ojima, 2006; Pishghadam \& Ghanizadeh, 2006; Al-Jarf, 2009; Negari, 2011; Riswanto \& Putra, 2012; Amer, 2013; Nobahar \& Tabrizi, 2013; Al-Shaer, 2014; Saed \& AL-Omari, 2014; Padang \& Gurning, 2014; Payman \& Gorjian, 2014; Meghyasi \& Hashamdar, 2015; Thayniath, 2015; Shakoori, Kadivar \& Sarami, 2017) and knowledge of text structure (e.g., Raphael \& Kirschner, 1985; Amer, 2013) on learners' writing performance.

It seems logical that the proposed strategy enhanced learners' communicative effectiveness (i.e., relevance and adequacy of content, compositional organization, cohesion, and adequacy of vocabulary for purpose) since it is mainly concerned with brainstorming adequate and relevant ideas and concepts (vocabulary), organizing them in a way that is characteristic of the text's top-level structure, and using conjunctions and transition signals that make the writing product cohesive. What is really surprising is that it also enhanced the accuracy (except for spelling) of learners' compositions. This effect can be explained in the light of De La Paz-Graham's (2002) assertion that knowing what to write and how to write it reduce the cognitive load on short-term, which, according to Ellis and Yuan (2004), allows greater attention when writers select lexical units and syntactic frames needed to encode ideas. Besides, the researcher used to mark students' essays and provide them with written feedback about such elements as grammatical accuracy and punctuation.

The only aspect that the experimental group did not improve significantly in comparison with the control group is spelling. Two reasons might explain this finding. First, experimental group students wrote much longer essays than those written by control group students. This might have increased the likelihood of making misspellings. Second, control group students, as revealed from the paired samples t-test, achieved significant improvement in spelling from pre- to post-testing. So did the experimental group students. That is, the experimental group significantly improved spelling from pre- to post-testing, but because the control group also did this, no significant difference was found between the posttest mean scores of the two groups concerning spelling.

Comparison of the writing performance of control group students before and after the experiment showed that they significantly improved some aspects of their writing, namely relevance and adequacy of content, punctuation and spelling. They also achieved higher means (though they did not reach a significance level) in compositional organization, grammar and the total score. A possible interpretation for this is that they also studied about 
text structure through reading exemplary texts. Besides, they wrote the same essays that the experimental group students wrote and received the same written feedback about the effectiveness and accuracy of their writing.

\section{Conclusion and implications}

Explicit teaching of concept mapping and text structure in the present study improved the various aspects of EFL students' writing, especially communicative effectiveness, i.e., including adequate and relevant ideas in well-developed cohesive essays. This is of particular significance for Arab EFL students who, as supported by a big body of research (Baka, 2013; Zakaria \& Mugaddam, 2013; Javid \& Umer, 2014; Abu Rass, 2015; Ahamed, 2016), have difficulties relevant to the communicative effectiveness of their writing. The researcher's personal experience and research findings assert that Arab EFL students cannot generate adequate ideas to write about and organize their ideas in well-developed compositions, so they end up with disconnected sentences, incoherent paragraphs and poorly-developed compositions. Training those students on concept mapping and using knowledge of text structure can make a big difference in their writing quality. It is, therefore, recommended that such training be integrated in writing courses offered to those students.

\section{References}

Abu Rass, Ruwaida. (2015). Challenges face Arab students in writing well-developed paragraphs. English Language Teaching, 8(10), 49-59. https://doi.org/10.5539/elt.v8n10p49

Ahamed, F. E. Yousuf. (2016). An investigation of writing errors of Saudi EFL university students (a case study of college of science \& arts- Tanumah, King Khalid university). International Journal of Social Science and Humanities Research, 4(2), 189-211.

Ahmed, H. (2010). Students' problems with cohesion and coherence in EFL essay writing in Egypt: Different perspectives. Literacy Information and Computer Education Journal, 1, 211-221. https://doi.org/10.20533/licej.2040.2589.2010.0030

Al Seyabi1, F. \& Tuzlukova, V. (2014). Writing problems and strategies: An investigative study in the Omani school and university context. Asian Journal of Social Sciences \& Humanities, 3(4).

Al-Jarf, R. (2009). Enhancing freshman students' writing skills with a mind mapping software. Paper presented at the 5th International Scientific Conference, eLearning and Software for Education, Bucharest.

Al-Khasawneh, F. \& Huwari, I. (2012). The reasons behind the weaknesses of writing in English among pre-year students' at Taibah University. English for Specific Purposes World, ISSN 1682-3257, http://www.esp-world.info, 38(4).

Almarwany, M. (2008). Writing difficulties of EFL secondary school students in Almunawwarh. Unpublished Master Thesis. Taibah University. 
Al-Shaer, I. (2014). Employing concept mapping as a pre-writing strategy to help EFL learners better generate argumentative compositions. International Journal for the Scholarship of Teaching and Learning, 8(2). https://doi.org/10.20429/ijsotl.2014.080210

Amer, M. (2013). The effect of explicit instruction in expository text structure on the writing performance of Arab EFL university students. AWEJ, 4(1), 224-238.

Arabloo, P. (2015). The comparative effect of individually created and collaboratively created concept maps on EFL learners' essay writing. Journal of Social Sciences, Literature and Languages, 1(1), 1-8.

Baka, F. (2013). Writing, an old-new problem for Arab learners in King Faisal university English major program. Scientific Journal of King Faisal University (Basic and Applied Sciences), 14(1).

Basturkmen, H. \& Lewis, M. (2002). Learner perspectives of success in an EAP writing course. Assessing Writing, 8, 31-46. https://doi.org/10.1016/S1075-2935(02)00032-6

Bourdin, B., \& Fayol, M. (2000). Is graphic activity cognitively costly? A developmental approach. Reading and Writing: An Interdisciplinary Journal, 13,183-196. https://doi.org/10.1023/A:1026458102685

Brown, D. (2003). High School biology: A group approach to concept mapping. The American Biology Teacher, 65 (3), 192-197. https://doi.org/10.2307/4451473

https://doi.org/10.1662/0002-7685(2003)065[0192:HSBAGA]2.0.CO;2

Brown, H. (2001). Teaching by principle: an interactive approach to language pedagogy. New York: Adisson-Wesley Longman: Cambridge University Press.

Brown, H. (2007). Principles of Language Learning and Teaching, 5th ed. USA: Pearson Education. Inc.

Chiu C. (2004). Evaluating system-based strategies for managing conflict in collaborative concept mapping. Journal of Computer Assisted Learning, 20, pp. 124-132, 2004. https://doi.org/10.1111/j.1365-2729.2004.00072.x

Chiu C. (2004). Evaluating system-based strategies for managing conflict in collaborative concept mapping. Journal of Computer Assisted Learning, vol. 20, pp. 124-132, 2004.

Cañas, A., Hoffman, R., Coffey, J. \& Novak, J. (2003). A summary of literature pertaining to the use of concept mapping techniques and technologies for education and performance support. The Institute for Human and Machine Cognition.

De La Paz, S., \& Graham, S. (2002). Explicitly teaching strategies, skills, and knowledge: Writing instruction in middle school classrooms. Journal of Educational Psychology, 94, 687-698. https://doi.org/10.1037/0022-0663.94.4.687

Doushaq, H. M. (1986). An investigation into stylistic errors of Arab students learning English for academic purposes. English for Specific Purposes, 5, 27-39. https://doi.org/10.1016/0889-4906(86)90005-0 
Dymock, S. (2005). Teaching expository text structure awareness: Teaching tips. The Reading Teacher, 59(2). https://doi.org/10.1598/RT.59.2.7

Ellis, R. \& Yuan, F. (2004). The effects of planning on fluency, complexity, and accuracy in second language narrative writing. Studies in Second Language Acquisition, 26(1), 59-84. https://doi.org/10.1017/S0272263104026130 https://doi.org/10.1017/S0272263104261034

Evans, S. and Green, C. (2007). Why EAP is necessary: A survey of Hong Kong tertiary students. Journal of English for Academic Purposes, 6(1), 3-17. https://doi.org/10.1016/j.jeap.2006.11.005

Fisher R. (1995). Teaching children to learn. Cheletham: Stanly Thornes.

Gaddy, S. Bakken, J. \& Fulk B. (2008). The effects of teaching text-structure strategies to postsecondary students with learning disabilities to improve their reading comprehension on expository science text passages. Journal of Postsecondary Education and Disability, 20(2).

Geva, E. (1983). Facilitating reading comprehension through flowcharts. TESOL Quarterly, (18(4), 384-404.

Goodnough, K. and Woods, R. (2002). Student and teacher perceptions of mind mapping: a middle school case study. Paper presented at the Annual Meeting of American Educational Research Association, New Orleans.

Grabe, W. (2002). Narrative and expository macro-genres. In A. M. Johns (Ed.), Genre in the classroom: Multiple perspectives. NJ: Lawrence Erlbaum Associates.

Grabe, W. (2009). Reading in a second language moving from theory to practice. Cambridge University Press.

Graham, S. \& Harris, K. (1996). Self-regulation and strategy instruction for students who find writing and learning challenging. In M. Levy and S. Ransdell (Eds.), The science of writing: Theories, methods, individual differences and applications, (pp. 347-360). Mahwah, NJ: Lawrence. Erlbaum.

Grami, G. (2010). The Effects of Integrating Peer Feedback into University-Level ESL Writing Curriculum: A Comparative Study in a Saudi Context. Doctoral dissertation submitted to Newcastle University, School of Education, Communication and Language Sciences. Available online https://theses.ncl.ac.uk/dspace/bitstream/10443/933/1/grami

Hazel, S. (2005). The Writing Experiment: Strategies for Innovative Creative Writing. Allen \& Unwin.

Hedge, T. (2008). Teaching and Learning in the Language Classroom. Oxford: Oxford University Press.

Henry, A., \& Roseberry, R.L. (1998). An evaluation of a genre-based approach to the teaching of EAP / ESP writing. TESOL Quarterly, 32(1), 147-156. https://doi.org/10.2307/3587913 
Henry, A., \& Roseberry, R.L. (1998). An evaluation of a genre-based approach to the teaching of EAP / ESP writing. TESOL Quarterly, 32(1), 147-156.

Jacobs, H., Zinkgraf, S., Wormuth, D., Hartfiel, V. \& Hughey, J. (1981). Testing ESL composition: A practical approach. Rowley, MA: Newbury House.

Javid, C. \& Umer, M. (2014). Saudi EFL learners' writing problems: a move towards solution. Proceeding of the Global Summit on Education GSE (E- ISBN 978-967-11768-5-6) Kuala Lumpur, MALAYSIA.

Kellog, R. (2008). Training Writing Skills: A Cognitive Development Perspective. USA.

Khan, I. (2011). Learning difficulties in English: Diagnosis and pedagogy in Saudi Arabia. Educational Research, 2(7), 1248-1257.

Kroll, B. (2001). Considerations for teaching an ESL/EFL Writing Course. In Marianne Celce-Murcia ( $3^{\text {rd }}$ Ed.), Teaching English as a Second or Foreign Language. USA: Heinle and Heinle Publishers.

Langan, J. (2008). College Writing Skills with Reading (7th Ed.). Singapore: McGraw-Hill Education.

Lee, Y. (2013). Collaborative concept mapping as pre-writing strategy for 12 learning: a Korean application. International Journal of Information and Education Technology, 3(2). https://doi.org/10.7763/IJIET.2013.V3.275

Lee, Y. (2013). Collaborative concept mapping as pre-writing strategy for 12 learning: a Korean application. International Journal of Information and Education Technology, 3(2).

Macaro, E. (2001). Learning strategies in foreign and second language classrooms. London and New York: Continuum.

Machida, N. \& Dalsky D. (2014). The effect of concept mapping on 12 writing performance: examining possible effects of trait-level writing anxiety. English Language Teaching; 7(9), 28-35. https://doi.org/10.5539/elt.v7n9p28

Meghyasi, M. \& Hashamdar, M. (2015). The Effect of Concept Mapping Strategies on Iranian EFL Learners' Descriptive and Persuasive Writing. International Journal of Educational Investigations, 2(7), 57-68.

Meyer, B. \& Poon, L. (2001). Effects of structure training and signaling on recall of text. Journal of Educational Psychology, 93, 141-159. https://doi.org/10.1037/0022-0663.93.1.141

Negari, J. (2011). A Study on strategy instruction and EFL learners' writing skill. International Journal of English Linguistics, 1(2), 299-307. https://doi.org/10.5539/ijel.v1n2p299

Nobahar, B. \& Tabrizi, A. (2013). The effect of concept mapping on Iranian intermediate EFL learners' self-efficacy and expository writing accuracy. Theory and Practice in Language Studies, 3(11), 2117-2127. https://doi.org/10.4304/tpls.3.11.2117-2127 
Novak J. (2004). Application of advances in learning theory and philosophy of science to the improvement of chemistry teaching. Journal of Chemical Education 61(7), 607-612. https://doi.org/10.1021/ed061p607

Novak, J. \& Ca-as, A. (2006). The origins of the concept mapping tool and the continuing evolution of the tool. Information Visualization Journal, 5(3), 175-184. https://doi.org/10.1057/palgrave.ivs.9500126

Novak, J. \& Cañas, A. (2008). The theory underlying concept maps and how to construct and use them. Florida Institute for Human and Machine Cognition Pensacola Fl, 1-36.

Nunan D. (2001). Second language teaching \& learning. Boston: Heinle \& Heinle.

Nunan, T. (2000). Exploring the Concept of Flexibility. In V. Jakupec and J. Garrick (eds.), Flexible Learning, Human Resource and Organizational Development: Putting Theory to Work. London: Routledge, pp. 47-66.

Ojima, M. (2006). Concept mapping as pre-task planning: A case study of three Japanese ESL writers. Journal of Science Direct System, 34, 566-585. https://doi.org/10.1016/j.system.2006.08.003

Okebukola, P. \& Jegede, O. (1989). Students' anxiety towards and perception of difficulty of some biological concepts under the concept-mapping heuristic. Research in Science \& Technological Education, 7(1), 85-92. https://doi.org/10.1080/0263514890070109

Okebukola, P. (1992). Concept mapping with a cooperative learning flavor. The American Biology Teacher, 54(4), 218-221. https://doi.org/10.2307/4449458

Padang, J. \& Gurning, B. (2014). Improving students' achievement in writing descriptive text through mind mapping strategy. Register Journal of English Language Teaching of FBS-Unimed, 3, 1-11.

Paykoç, F., Mengi, B., Kamay, P., Onkol, P., Ozgur, B., Pilli, O. and Yildirim, H. (2004). What are the major curriculum issues? The use of mind mapping as a brainstorming exercise. Paper presented at the First Int. Conference on Concept Mapping, Spain.

Payman, S. \& Gorjian, B. (2014). Effects of task-based strategies on students' writing skill among translation students. European Journal of Business and Social Sciences, 3(3), 201-216.

Peregoy, S. and Boyle, O. (2005), Reading, writing and learning in ESL (4th Ed.). Boston: Pearson Education Inc.

Pishghadam, R. \& Ghanizadeh, A. (2006). On the impact of concept mapping as a prewriting activity on EFL learners' writing ability. Iranian Journal of applied linguistics (IJAL), 9 (2), 101-126.

Raphael, T. \& Kirschner, B. (1985). The effects of instruction in compare/contrast text structure on sixth-grade students' reading comprehension and writing products. IL, Chicago: 
Paper presented at the Annual Meeting of the American Educational Research Association (ERIC Document Reproduction Service No. ED264537).

Reppen, R. (1995). A genre-based approach to content writing instruction, TESOL Journal, 4, 2, 32-35.

Richards J. \& Renadya, W. (2002). Methodology in language teaching: Anthology of current practice. Cambridge University Press. https://doi.org/10.1017/CBO9780511667190

Richards, J. (1990). The Language Teaching Matrix. Cambridge: Cambridge University Press. https://doi.org/10.1017/CBO9780511667152

Richards, J., Platt, J. \& Platt, H. (1992). Dictionary of Language Teaching \& Applied Linguistics. (2 ${ }^{\text {nd }}$ Ed.), Harlow, Essex: Longman.

Richardson, P. (2004). Possible influences of Arabic-Islamic culture on the reflective practices proposed for an education degree at the Higher Colleges of Technology in the United Arab Emirates. International Journal of Educational Development, 24, 429-436. https://doi.org/10.1016/j.ijedudev.2004.02.003

Riswanto, S. \& Putra, P. (2012). The use of mind mapping strategy in the teaching of writing at SMAN 3 Bengkulu, Indonesia. International Journal of Humanities and Social Science, 2(21), 60-68.

Saed, H. \& AL-Omari H. (2014). The effectiveness of a proposed program based on a mind mapping strategy in developing the writing achievement of eleventh grade EFL students in Jordan and their attitudes towards writing. Journal of Education and Practice, 5(18), 88-110.

Salem, M. (2007). The effect of journal writing on written performance, writing apprehension, and attitudes of Egyptian English majors. Unpublished Ph. D Dissertation, the Pennsylvania State University.

Schwendimann, B. (2015). Concept maps as versatile tools to integrate complex ideas: From kindergarten to higher and professional education. Knowledge Management \& E-Learning: Special Issue on Novakian Concept Mapping in University and Professional Education, 7(1), 73-99.

Seow, A. (2002). The writing process and the process writing. Richards, J. Renandya, W. (Ed.) Methodology in Language Teaching: An Anthology of Current Practice. Cambridge: Cambridge University Press, pp, 315-320. https://doi.org/10.1017/CBO9780511667190.044

Shakoori. M, Kadivar. P, \& Saram, R. (2017). The effect of concept mapping strategy as a graphical tool in writing achievement among EFL learners. International Journal of Information and Education Technology, 7(5), 357-360. https://doi.org/10.18178/ijiet.2017.7.5.894

Shukri, N. (2014). Second Language Writing and Culture: Issues and Challenges from the Saudi Learners' Perspective. AWEJ, 5(3), 190-207. 


\section{Macrothink}

Journal of Studies in Education

ISSN 2162-6952

2017, Vol. 7, No. 2

Smalley, Regina L., Ruetten, M. \& Kozyrev, J. (2001). Refining Composition Skills: Rhetoric and Grammar $\left(5^{\text {th }}\right.$ Ed). Boston: Heinle \& Heinle.

Spring, C. \& Prager, J. (1992). Teaching community college students to follow the train of thought in expository texts. Reading and Writing, An interdisciplinary Journal, 4: 33-54. https://doi.org/10.1007/BF01027071

Taylor, B. \& Beach, R. (1984). The effects of text structure instruction on middle grade students, comprehension and production of expository text. Reading Research Quarterly, 19(2), 134-145. https://doi.org/10.2307/747358

Thayniath, S. (2015). A study on strategy instruction for undergraduate Engineers' writing skill. IMPACT: International Journal of Research in Humanities, Arts and Literature, 3(4), 37- 48 .

Villalon, J. \& Calvo R. A. (2011). Concept Maps as Cognitive Visualizations of Writing Assignments. Educational Technology \& Society, 14 (3), 16-27.

Weigle, S. (2002). Assessing writing. Cambridge, UK: Cambridge University Press. https://doi.org/10.1017/CBO9780511732997

Weir, C. (1990). Communicative language testing. Englewood Cliffs, NJ: Prentice Hall Regents.

Yunus, M. \& Chien, C. (2016). The use of mind mapping strategy in Malaysian university English test (MUET) Writing. Creative Education, 7, 619-626. https://doi.org/10.4236/ce.2016.74064

Zakaria, A. \& Mugaddam, A. (2013). An assessment of the written performance of the Sudanese EFL university learners: a communicative approach to writing. World Journal of English Language, 3(4), 1-10. https://doi.org/10.5430/wjel.v3n4p1

Zhang, S. (2009). The role of input, interaction and output in the development of oral fluency. English Language Teaching, 2(4), 91-100. https://doi.org/10.5539/elt.v2n4p91

Zimmaro, D. \& Cawley, J. (1998). Concept map module. Schreyer institute for innovation in learning, The Pennsylvania State University. 
Appendix (1a). A concept map the researcher developed in collaboration with students

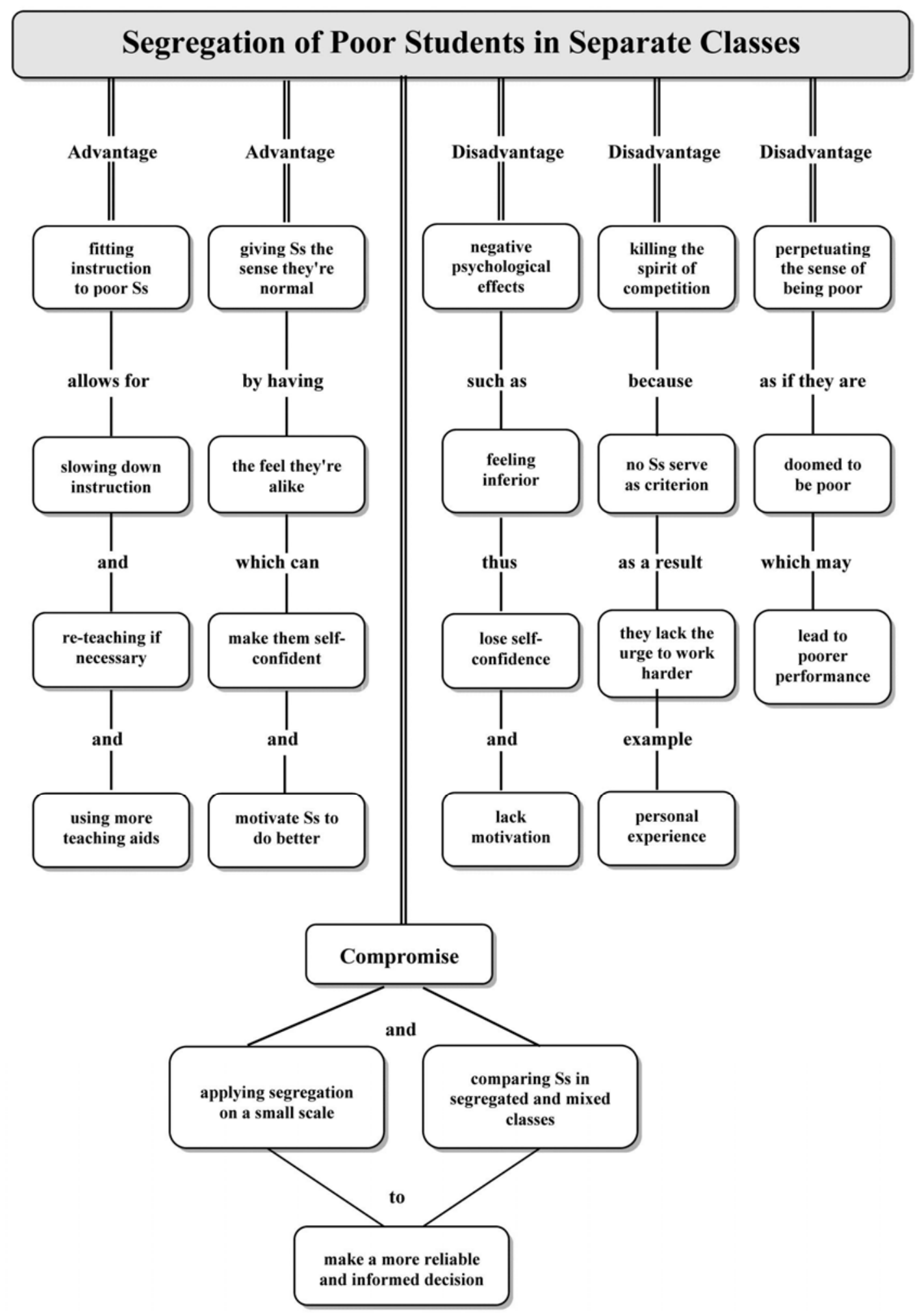


Appendix (1b). An empty template the researcher developed in collaboration with students

\section{Topic: segregation of poor students in separate classes}

$\begin{array}{ll}\text { Introduction } & \\ \text { Introductory sentences } & \neq \\ \text { Thesis/claim } & \neq 2 \\ & \neq 3 \\ & \neq 4 \\ & \neq 5\end{array}$

Body Paragraph 1

(disadvantages of

\section{segregation)}

Introductory sentence

A disadvantage

$\neq 1$

Elaboration

Elaboration

Support

$\neq 4$

A disadvantage

$\neq 5$

Elaboration

$\neq 6$

Elaboration

$\neq 7$

Elaboration

$\neq 8$

Support

$\neq 10$

A disadvantage

$\neq 11$

Elaboration

$\neq 12$

Elaboration

$\neq 13$

Elaboration

$\neq 14$

Support

$\neq 15$

Elaboration

$\neq 16$

Body Paragraph 2

(advantages of

segregation)

Introductory sentence

Advantage

Elaboration

$\neq 3$

Elaboration

$\neq 4$

Elaboration

$\neq 5$.

Elaboration

$\neq 6$

Elaboration

$\neq 7$

Elaboration

$\neq 8$

Advantage

$\neq 9$

Elaboration

$\neq 10$

Support

$\neq 11$

Elaboration

$\neq 12$

Conclusion 


$\begin{array}{ll} & \neq 2 \\ \text { Compromise } & \neq 3 \\ \text { Elaboration } & \neq 4 \\ \text { Elaboration } & \neq 5 \\ \text { Elaboration } & \neq 6 \\ \text { Elaboration } & \neq 7\end{array}$


Appendix (1c). The template completed by the researcher in collaboration with students

Topic: segregation of poor students in separate classes

\section{Introduction}

Introductory sentences

$\neq 1$ educational institutes aim to create a supportive environment to maximize the learning of all students (for this reason)

$\neq 2$ they usually attempt new ideas to achieve the desired outcomes

Thesis/claim $\neq 3$ my college plans to put good and poor students in separate classrooms $\neq 4$ this has both advantages and disadvantages (however) $\neq 5$ these advantages and disadvantages should be weighed to come up with the right decision.

Body Paragraph 1

(disadvantages of segregation)

Introductory sentence

\section{A disadvantage \\ Elaboration \\ Elaboration \\ Support}

\section{A disadvantage \\ Elaboration \\ Elaboration \\ Elaboration \\ Support}

A disadvantage

Elaboration

Elaboration

Elaboration

Support

Elaboration

Body Paragraph 2

\section{(advantages of} segregation) Introductory sentence Advantage

Elaboration

Elaboration $\neq 1$ apart from the fact that segregation is against human rights, it has many disadvantages that should be taken into account

$\neq 2$ segregating poor students can have negative psychological effects on students $\neq 3$ putting poor students in special classrooms can make them feel inferior $\neq 4$ this can demotivate them and affect their learning badly $\neq 5$ studies proved that individuals who lack self-assurance are not likely to be successful even though they have the potential and capabilities to achieve success (Ref.)

$\neq 6$ putting poor students in special classrooms kills the spirit of competition in them $\neq 7$ when in the same class, many poor students aspire to be good too $\neq 8$ this can motivate them to exert more efforts to do better $\neq 9$ that is, they work hard to keep pace with good students

$\neq 10$ Everyday life experiences assert states that competition is one of the most powerful incentives to work

$\neq 11$ poor students may give in and accept the untrue fact that they are poor and will remain so (as a result)

$\neq 12$ students get frustrated

$\neq 13$ when students give in, teachers efforts fail no matter how intensive and sincere they may be (moreover)

$\neq 14$ students may begin to display behavior problems to avoid academic activities that they see as useless

$\neq 15$ research has revealed that unsuccessful learners show more behavior problems than successful ones (Ref.) (thus)

$\neq 16$ instead of solving the problem of poor learning, other types of problems are created, especially psychological and behavioral ones

$\neq 1$ on the other hand, putting poor students in special classrooms can have advantages

$\neq 2$ teachers can fit their instruction to poor students

$\neq 3$ they can slow down the pace of their instruction to suit the capabilities of students (also)

$\neq 4$ they can re-teach difficult areas of the content several times until students grasp them 
Elaboration

Elaboration

Elaboration

Elaboration

Advantage

Elaboration

Support

Elaboration

\section{Conclusion}

Introductory sentences

Compromise

Elaboration

Elaboration

Elaboration

Elaboration $\neq 5$ some people claim that this fitting of instruction cannot occur in mixed classes as it can harm the learning of good students (but)

$\neq 6$ this claim is questionable

$\neq 7$ teachers can get poor students to do extra work through home assignments (besides)

$\neq 8$ they can allocate some more classes (e.g., a class per week) to re-teach difficult areas of the content to poor students

$\neq 9$ attending classes with students from the same level can give poor students the sense that they are normal

$\neq 10$ this can strengthen their self-confidence

$\neq 11$ several studies have shown that beliefs about self-efficacy have good reflections on students' learning (find reference)

$\neq 12$ teachers can exploit this sense and motivate poor students to work harder to better their learning

$\neq 1$ in brief, putting poor students in special classrooms has both advantages and disadvantages

(however)

$\neq 2$ disadvantages outnumber advantages and are more serious

$\neq 3$ a good idea that the college may attempt is to try separation on a small scale

$\neq 4$ that is, the college can allocate just one classroom for poor students as a trial

$\neq 5$ the performance of students in this classroom can be compared with the performance of poor

students in multi-level classrooms (besides)

$\neq 6$ comparison should cover students' behavior in both settings

$\neq 7$ the separation idea can then be accepted or rejected based on the results of the comparison 
Appendix (1d). The essay based on the developed concept map and the template

Educational institutes aim to create supportive environments to maximize the learning of all students. For this reason, they usually attempt new ideas to achieve the desired outcomes. In this respect, my college plans to put good and poor students in separate classrooms. In my opinion, this has both advantages and disadvantages. These advantages and disadvantages should be weighed to come up with the right decision.

Apart from the fact that segregation is against human rights, it has many disadvantages that should be taken into account. One disadvantage of allocating special classrooms for poor students is that it can have negative psychological effects on students. Putting poor students in special classrooms can make them feel inferior. This, in turn, can demotivate them and affect their learning badly. Studies proved that individuals who lack self-assurance are not likely to be successful even though they have the potential and capabilities to achieve success (Stevens, 2005). Another disadvantage is that putting poor students in special classrooms kills the spirit of competition in them. Attending in the same classes with good students, many poor students aspire to be good too. This can motivate them to exert more efforts to do better. That is, they work hard to keep pace with good students. Everyday life experiences assert that competition is one of man's most powerful incentives to work.

A third disadvantage is that poor students may give in and accept the untrue fact that they are poor and will remain so. As a result, they get frustrated. When students give in, teachers' efforts fail no matter how intensive and sincere they may be. In this respect Salancik (1977) suggests that when people expect to fail they fail quite effectively, and failure leads to failure more readily for individuals characterized with low self-esteem. Moreover, students may begin to display behavior problems to avoid academic activities that they see as useless. Research has revealed that unsuccessful learners show more behavior problems than successful ones (Williams \& McGee, 1994). Thus, instead of solving the problem of poor learning, other types of problems are created, especially psychological and behavioral ones.

On the other hand, putting poor students in special classrooms can have advantages. First, teachers can fit their instruction to poor students. They can slow down the pace of their instruction to suit the capabilities of poor students. Also, they can re-teach difficult areas of the content several times until students grasp them. Some people claim that this fitting of instruction cannot occur in mixed classes as it can harm the learning of good students. But this claim is questionable. Teachers can get poor students to do extra work through assignments. Besides, they can allocate some more classes (e.g., a class per week) to re-teach difficult areas of the content to poor students. Second, attending classes with students from the same level can give poor students the sense that they are normal. This can strengthen their self-confidence. Several studies have shown that beliefs about self-efficacy have good reflections on students' learning (Bandura, 1986). Teachers can exploit this sense and motivate poor students to work harder to better their learning.

In brief, putting poor students in special classrooms has both advantages and disadvantages. However, disadvantages outnumber advantages and are more serious. Yet, a good idea that the college may attempt is to try separation on a small scale. That is, the college can allocate just one classroom for poor students as a trial. The performance of students in this classroom can be compared with the performance of poor students in multi-level classrooms. Besides, comparison should cover students' behavior in both settings. The separation idea can then be accepted or rejected based on the results of the comparison. A decision based on data is supposed to be more reliable and more informed. 
Appendix 2. The rating scale (Weir, 1990)

A. Relevance and adequacy of content

0 The answer bears almost no relation to the task set. Totally inadequate answer.

1 Answer of limited relevance to the task set. Possibly major gaps in the treatment of topic and/or pointless repetition.

2 For the most part answers the tasks set, though there may be some gaps or redundant information.

3 Relevant and adequate answer to the task set.

B. Compositional organization

0. No apparent organization of content.

1. Very little organization of content. Underlying Structure not sufficiently controlled.

2. Some organizational skills in evidence, but not adequately controlled.

3. Overall shape and internal pattern clear. Organizational skills adequately controlled.

C. Cohesion

0 Cohesion almost totally absent. Writing so fragmentary that comprehension of the intended communication is virtually impossible.

1. Unsatisfactory cohesion may cause difficulty in comprehension of most of the intended communication.

2. For the most satisfactory cohesion although occasional deficiencies may mean that certain parts of the communication are not always effective.

3. Satisfactory use of cohesion resulting in effective communication.

D. Adequacy of vocabulary for purpose

0. Vocabulary inadequate even for the most basic parts of the intended communication.

1. Frequent inadequacies in vocabulary for the task. Perhaps frequent lexical inappropriacies and/or repetition.

2. Some inadequacies in vocabulary for the task. Perhaps some lexical inappropriacies and/or circumlocution.

3. Almost no inadequacies in vocabulary for the task. Only rare inappropriacies and/ or circumlocution.

E. Grammar
0. Almost all grammatical patterns inaccurate.
1. Frequent grammatical inaccuracies.
2. Some grammatical inaccuracies.
3. Almost no grammatical inaccuracies.

F. Mechanical accuracy I (punctuation)
0 . Ignorance of conventions of punctuation.
1. Low standard of accuracy in punctuation.
2. Some inaccuracies in punctuation.
3. Almost no inaccuracies in punctuation.

G. Mechanical accuracy II (spelling)
0 . Almost all spelling inaccurate.
1. Low standard of accuracy in spelling.
2. Some inaccuracies in spelling.
3. Almost no inaccuracies in spelling. 